\title{
Update on Pediatric Tracheostomy: Indications, Technique, Education, and Decannulation
}

\author{
Colin Fuller ${ }^{1,2} \cdot$ Andre' M. Wineland $^{1,2} \cdot$ Gresham T. Richter $^{1,2}$ \\ Accepted: 3 March 2021 / Published online: 15 April 2021 \\ (C) The Author(s), under exclusive licence to Springer Science+Business Media, LLC, part of Springer Nature 2021
}

\begin{abstract}
Purpose of Review Tracheostomy in a child demands critical pre-operative evaluation, deliberate family education, competent surgical technique, and multidisciplinary post-operative care. The goals of pediatric tracheostomy are to establish a safe airway, optimize ventilation, and expedite discharge. Herein we provide an update regarding timing, surgical technique, complications, and decannulation, focusing on a longitudinal approach to pediatric tracheostomy care.

Recent Findings Pediatric tracheostomy is performed in approximately $0.2 \%$ of inpatient stays among tertiary pediatric hospitals. Mortality in children with tracheostomies ranges from 10-20\% due to significant comorbidities in this population. Tracheostomy-specific mortality and complications are now rare. Recent global initiatives have aimed to optimize decisionmaking, lower surgical costs, reduce the length of intensive care, and eliminate perioperative wound complications. The safest road to tracheostomy decannulation in children remains to be both patient and provider dependent.

Summary Recent literature provides guidance on safe, uncomplicated, and long-term tracheostomy care in children. Further research is needed to help standardize decannulation protocols.
\end{abstract}

Keywords Tracheostomy $\cdot$ Pediatrics $\cdot$ Trachea $\cdot$ Bronchopulmonary Dysplasia $\cdot$ Clinical Reviews

\section{Introduction}

Lorenz Heister introduced the term "tracheostomy" in 1718 to describe the opening, maturation, and insertion of an indwelling tube through the neck into the trachea. Since then, numerous surgical and medical disciplines have advanced the

This article is part of the Topical collection on PEDIATRIC OTOLARYNGOLOGY: Pediatric Airway and Voice

Colin Fuller

cwfuller@uams.edu

Andre' M. Wineland

winelandandrem@uams.edu

Gresham T. Richter

gtrichter@uams.edu

1 Department of Otolaryngology, Head and Neck Surgery, University of Arkansas for Medical Sciences, 1 Children's Way, Little Rock, AR 72202, USA

2 Division of Pediatric Otolaryngology, Arkansas Children's Hospital, Little Rock, AR, USA implementation and maintenance of the surgical airway. In children, both otolaryngologists and pediatric surgeons are adept at establishing a tracheostomy, while various hospital teams support other critical aspects of long-term stoma care, family education, supplies, and (if necessary) chronic mechanical ventilation. Responsibility for each element of perioperative and long-term care may differ from one hospital to another. However, recent consensus guidelines allow for a more systematic and consistent approach to the care of these patients despite the array of disciplines involved $[1 \bullet \bullet, 2 \bullet \cdot]$. This review offers general knowledge, operative considerations, wound care suggestions, and long-term strategies for pediatric tracheostomy based upon current literature. Controversies and discussion on decannulation protocols will also be addressed.

\section{Overview}

Tracheostomy is estimated to be performed in about $0.2 \%$ of pediatric inpatient stays [3•]. Historically, acute upper airway obstruction from infectious or inflammatory causes was the 
most common indication for pediatric tracheostomy. Today, due in part to widespread vaccination for $H$. influenza, this indication is far less common [4].

The survivability of extreme prematurity, bronchopulmonary dysplasia, and other complex cardiopulmonary conditions in the neonate continues to improve. From 2007 to 2015, in-hospital mortality improved from 9.9 to $8.2 \%$ among pre-term low birthweight infants in all eleven high-income countries studied [5]. As the worldwide care for premature and medically complex newborns improves, the most common indication for pediatric tracheostomy is now the need for long-term ventilation [3•].

Multidisciplinary input regarding the prognosis of a tracheostomy candidate should be established with the healthcare team and family before proceeding to surgery unless the indication for tracheostomy is urgent. The procedure is the first step in a long process of transitioning ventilatory care from the hospital to home. A well-orchestrated use of hospital services and education is necessary to facilitate this process, which places a unique burden of responsibility on patient families [6-8].

Post-operative morbidity and mortality from tracheostomy are often related to deteriorating medical comorbidities and rarely device-related complications $\left[9 \bullet, 10^{\bullet}\right]$. However, there remain significant risks of improper care and monitoring of the patient, including accidental decannulation or mucus plugging of the tube. Thus, pediatric healthcare providers should familiarize themselves with routine tracheostomy care especially in practice settings with medically complex patients. Tracheostomy care is a longitudinal investment by families, providers, and institutions to prevent complications both in the hospital and at home (Fig. 1). The purpose of this review is to describe the indications for tracheostomy, surgical technique, post-operative care, and decannulation strategies.

\section{Pre-operative Evaluation}

\section{Indications}

A tracheostomy is useful for bypassing acute or chronic upper airway obstruction. Although rarely used as a first-line intervention, a tracheostomy can also be the final step in the management of severe obstructive sleep apnea (OSA). A tracheostomy replaces an endotracheal tube for those who require long-term mechanical ventilation. In patients who have poor secretion management and chronic aspiration, a tracheostomy will provide access to deep pulmonary suctioning. In patients with either congenital or iatrogenic subglottic stenosis, a tracheostomy can help bypass this obstruction.

Retrospective studies have shown that the incidence of tracheostomy in children is gradually increasing [3•,11, 12•], though this may be due, in part, to increases in patient population and widening participation in administrative databases. Gergin et al. reported that cardiopulmonary and neurologic indications for tracheostomy have seen the greatest rise over 30 years. Craniofacial and traumatic indications for surgery have demonstrated only modest increases. The most common indication varies with the age of the patient. Children with complicated cardiopulmonary, craniofacial, or upper airway conditions were likely to undergo tracheostomy between the ages of 4 to 6 months, whereas patients with neurological disorders or trauma where more likely to receive a tracheostomy between the ages of 2 to 3 years.

\section{Contraindications}

Strict contraindications to pediatric tracheostomy are uncommon. Relative contraindications include an anterior neck mass obstructing access, a severely medically unstable patient, a high-riding innominate artery, and very poor long-term prognosis. In patients with a poor prognosis, an ethical dilemma may arise. Patient families may be intent on exploring all lifeprolonging therapies even at the potential expense of the patient's and family's quality of life. For this reason, a provider may recommend against tracheostomy when interventions are considered futile for survivability.

Nonetheless, a tracheostomy can reduce the encumbrances of sedation and allow for wakeful interaction of the child with their caregivers. Tracheostomy may be thereby advocated as a palliative measure in children with poor short-term prognoses and a need for mechanical ventilation [13] as seen in patients with severe forms of spinal muscular atrophy (SMA). Surgeons should be aware that subtypes of this historically fatal progressive neurodegenerative disease have

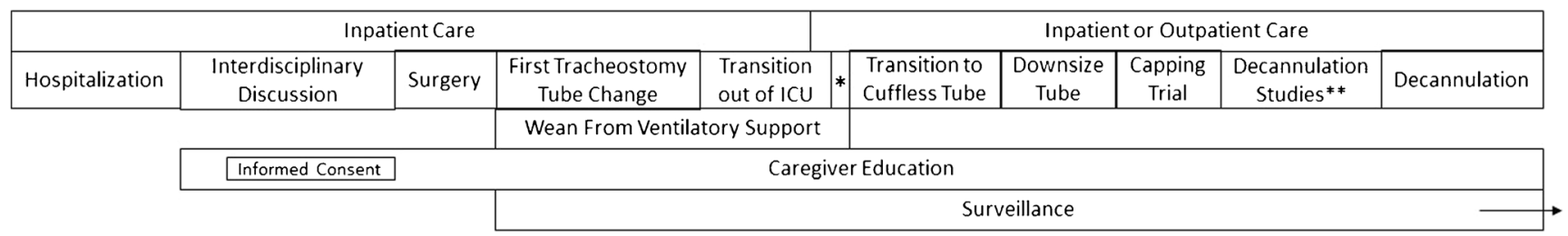

Fig. 1 Proposed timeline for the care of the patient undergoing nonemergent tracheostomy, from the initial hospitalization through decannulation. Single asterisk "*: Transition off of mechanical ventilatory support is a process of variable length and can take years in younger patients with severe bronchopulmonary dysplasia. Double asterisk "**": Pre-decannulation studies can include polysomnogram and/or upper and lower airway endoscopy 
demonstrated dramatic improvement with new gene therapies $[14,15]$. Incorporation of a medical ethics team into the discussion is recommended in controversial cases.

\section{Care Coordination}

Care for pediatric patients with a tracheostomy can be very challenging due to the medical complexity of these patients and the direct trials of home tracheostomy management [6-8]. Thus, a clear and open multidisciplinary discussion with the family is warranted prior to surgery and should address the patient's long-term prognosis, short-term risks, and costs associated with long-term tracheostomy care. Multidisciplinary members present during this discussion include the surgical team, intensive care, palliative care, pulmonology, psychology, nursing, and social work. Additional input from members of the patient's subspecialty care may prove necessary in terms of the patient's acute and long-term prognosis.

Patient-specific discharge planning must also be discussed. Pediatric patients with a tracheostomy must have at least one tracheostomy trained adult caregiver present and ready to intervene at any time in case of an emergency. These caregivers must navigate initially unfamiliar medical equipment to deliver proper care. The presence of a tracheostomy may make other family members uncomfortable and unsuitable as a primary caregiver(s). All of these challenges can have a significant impact on the family member(s) health, emotional wellbeing, sleep, and intra- and inter-familial relationships [6]. Families should be fully aware of these expectations prior to surgery and this discussion should be considered part of the informed consent process.

\section{Predictors of Mortality}

When compared to adults, pediatric tracheostomy is associated with higher rates of mortality. The discrepancy can be explained by the degree of medical complexity in children requiring tracheostomies. There is a wide variety of reported mortality rates from $0 \%$, in a cohort of patients undergoing surgery for OSA, to $26 \%$ for those with hypoplastic left heart syndrome $[3 \bullet, 9 \bullet, 10 \bullet, 12 \bullet, 16 \bullet, 17 \bullet, 18 \bullet, 19 \bullet, 20 \bullet, 21 \bullet]$. (Table 1) Most of these studies report mortality rates of 10 $20 \%$ for all-cause after at least 1 year, while one study reported a mortality rate prior to discharge of $8.6 \%[3 \bullet]$. However, there is a current trend toward improving mortality rates in tracheostomy patients $[9 \bullet, 17 \bullet]$, which is likely related to global initiatives improving the care of these complex patients.

Tracheostomy-specific mortality is low, though not-insignificant, at rates reported from $0-3.5 \%[9 \bullet, 10 \bullet]$. Only two recent studies reported a total of seven tracheostomy-related deaths. All of these were related to either mucus plugging or accidental decannulation. It should be recognized that these events are of greater risk in the pediatric population due to the lack of an inner tracheostomy cannula and smaller airway anatomy. Risk factors for these rare events have not been fully examined, in part due to their rarity.

\section{Comorbidities}

Children who undergo tracheostomy due to underlying neoplasm or congenital cardiac anomalies tend to have higher mortality than those children who undergo tracheostomy due to underlying pulmonary disease $[3 \cdot, 9 \bullet, 16 \bullet]$. Neurologic comorbidities in some studies have been linked to poor outcomes, though others report no increased risk (Table 1).

\section{Weight}

The weight itself has not proven to be a significant predictor of poor outcomes after tracheostomy. A NSQIP database review of children less than 2 years of age undergoing tracheostomy [20•] demonstrated that weight less than $2.5 \mathrm{~kg}$ at the time of surgery did not confer a higher risk of mortality or complications in the first 30 days post-operatively. On multivariate logistic regression, the only predictor of poor outcomes in this group was the presence of bronchopulmonary dysplasia (BPD).

\section{Age}

Age at the time of tracheostomy is not conclusively a risk factor for all-cause mortality. Studies that include the neonatal intensive care unit (NICU) population demonstrate worse outcomes with earlier age at the time of surgery $[3 \bullet, 16 \bullet 21 \bullet]$. However, research specific to the pediatric intensive care unit (PICU) setting does not show the same risk in younger patients $\left[10^{\bullet}, 18^{\bullet}\right]$. This difference is likely to be related to different indications for surgery between the units and their underlying patient comorbidities, such as BPD in the newborn.

\section{Tracheostomy Timing}

Inability to extubate or failure to remain extubated is the most common pediatric indication for tracheostomy, and consideration of tracheostomy candidacy is typically initiated by the intensivist. Once the surgical team has evaluated the patient, a family meeting should be organized and an introduction to tracheostomy care should commence.

A recent survey [22] of Canadian pediatric intensivists, neonatologists, pulmonologists, and otolaryngologists revealed that practice patterns have shifted toward recommending earlier tracheostomy compared to 11 years prior [23]. A recent meta-analysis [24] identified eight retrospective studies evaluating outcomes of early versus late tracheostomy in mechanically ventilated patients. While the early tracheostomy group had statistically significant reductions 
Table 1 Recent publications, pediatric post-tracheostomy mortality

\begin{tabular}{|c|c|c|c|c|c|c|}
\hline $\begin{array}{l}\text { Primary } \\
\text { author, year }\end{array}$ & $N$ & Design & $\begin{array}{l}\text { Specific pediatric } \\
\text { population }\end{array}$ & Risk factors for mortality & $\begin{array}{l}\text { Mortality rate } \\
\text { (timeframe) }\end{array}$ & $\begin{array}{l}\text { Tracheostomy- } \\
\text { related mortality } \\
\text { rate (timeframe) }\end{array}$ \\
\hline $\begin{array}{l}\text { Watters, } \\
2016 \\
{[16 \cdot]}\end{array}$ & 502 & $\begin{array}{l}\text { Retrospective } \\
\text { cohort }\end{array}$ & Medicaid pts $<16$ y/o & Hispanic, younger age at tracheostomy & $9.0 \%$ (2 year) & - \\
\hline $\begin{array}{l}\text { Funamura, } \\
2016[9 \bullet]\end{array}$ & 513 & $\begin{array}{l}\text { Retrospective } \\
\text { cohort }\end{array}$ & - & $\begin{array}{l}\text { Older age, } \mathrm{BPD}, \mathrm{CHD} \text {, infection, } \\
\text { neoplasia, chronic mechanical } \\
\text { ventilation, tracheostomy prior to } \\
2010\end{array}$ & $16.6 \%$ (indefinite) & $3.5 \%$ (indefinite) \\
\hline $\begin{array}{r}\text { Tsuboi, } \\
2016 \\
{[10 \bullet]}\end{array}$ & 212 & $\begin{array}{l}\text { Retrospective } \\
\text { cohort }\end{array}$ & $\begin{array}{l}\text { PICU patients, } \\
\text { neurologically } \\
\text { impaired vs intact }\end{array}$ & Neoplasia & $\begin{array}{l}14 \% \text { (1 year), } 29 \% \\
\quad(5 \text { year) }\end{array}$ & $1.9 \%$ (indefinite) \\
\hline $\begin{array}{l}\text { Dal'Astra, } \\
\text { 2017* } \\
{[17 \cdot]}\end{array}$ & 5933 & $\begin{array}{l}\text { Meta-analysis, } \\
\text { stratified by } \\
\text { decade of } \\
\text { publication }\end{array}$ & - & - & $10.6 \%$ (various) & $0.9 \%$ (various) \\
\hline $\begin{array}{l}\text { McPherson } \\
2017 \\
{[18 \bullet]}\end{array}$ & 426 & $\begin{array}{l}\text { Retrospective } \\
\text { cohort }\end{array}$ & PICU patients & $\begin{array}{l}\text { Acquired neurologic, congenital } \\
\text { neurologic, and congenital respiratory } \\
\text { comorbidities }\end{array}$ & $23 \%$ (indefinite) & - \\
\hline $\begin{array}{l}\text { Rizzi, } 2017 \\
{[19 \bullet]}\end{array}$ & 29 & Case series & $\begin{array}{l}\text { Severe OSA } \\
\text { indicating } \\
\text { tracheostomy }\end{array}$ & - & $0 \%$ (indefinite) & $0 \%$ (indefinite) \\
\hline $\begin{array}{l}\text { Prodhan, } \\
2017 \\
{[12 \bullet]}\end{array}$ & 126 & $\begin{array}{l}\text { Retrospective } \\
\text { cohort }\end{array}$ & History of HLHS & - & $26 \%$ (indefinite) & - \\
\hline $\begin{array}{l}\text { Rawal, } \\
2019 \\
{[20 \bullet]}\end{array}$ & 543 & $\begin{array}{l}\text { Retrospective } \\
\text { cohort }\end{array}$ & $\begin{array}{l}\text { Stratified by weight at } \\
\text { surgery }(<2.5 \mathrm{~kg} \\
2.5-4 \mathrm{~kg},>4 \mathrm{~kg})\end{array}$ & - & $4.3 \%$ (30 day) & - \\
\hline $\begin{array}{l}\text { Han, } 2020 \\
{[21 \cdot]}\end{array}$ & 3442 & $\begin{array}{l}\text { Prospective } \\
\text { cohort }\end{array}$ & $\begin{array}{l}\text { Neonates with very } \\
\text { low birthweight, } \\
\text { stratified by } \\
\text { birthweight }\end{array}$ & $\begin{array}{l}\text { Birth weight }<750 \mathrm{~g} \text {, male sex, CLD, } \\
\text { neurologic comorbidity, cardiac } \\
\text { comorbidity, chromosomal } \\
\text { comorbidity }\end{array}$ & $\begin{array}{l}18.5 \%(1 \text { year } \\
\text { in-hospital } \\
\text { mortality rate })\end{array}$ & - \\
\hline $\begin{array}{l}\text { Friesen, } \\
2020[3 \bullet]\end{array}$ & 14,155 & $\begin{array}{l}\text { Retrospective } \\
\text { cohort }\end{array}$ & $\begin{array}{l}\text { All pediatric patients } \\
\text { in the PHIS } \\
\text { database }\end{array}$ & $\begin{array}{l}\text { Younger age, Asian, Northeast region, } \\
\text { cardiac, hematologic, metabolic, } \\
\text { urologic comorbidities, prematurity }\end{array}$ & $\begin{array}{c}8.6 \% \text { (pre-discharge } \\
\text { mortality rate) }\end{array}$ & - \\
\hline
\end{tabular}

Summary of mortality rates in studies published since 2016

*Data from the most recent era (2005-2014) are here reported. $N$, number of patients in the cited study; pts, patients; $y / o$, year old; $B P D$, bronchopulmonary dysplasia; $C H D$, congenital heart disease; $P I C U$, pediatric intensive care unit; OSA, obstructive sleep apnea; HLHS, hypoplastic left heart syndrome; $\mathrm{kg}$, kilogram; $C L D$, congenital lung disease; $P H I S$, pediatric health information system

in days of mechanical ventilation, ICU stay, hospital stay, and hospital-acquired pneumonia, the improvement in risk of mortality did not reach statistical significance.

\section{Surgical Technique}

\section{Securing the Airway, Positioning, and Incision Placement}

The patient is transferred onto the operating room table and routine cardiopulmonary monitoring devices are placed. Once general anesthesia has been induced a microlaryngoscopy and bronchoscopy (MLB) may be performed to assess and size the airway to aid in choosing the proper tracheostomy size. When appropriate, an appropriately sized cuffed endotracheal tube is then placed and secured. The patient is then positioned with a small shoulder roll to place the neck into extension. The sternal notch, cricoid cartilage, and thyroid cartilage help identify the midline. Midway between the cricoid cartilage and sternal notch is a relatively good rule for marking the planned tracheostomy incision. An incision too low can later contribute to a "key-hole deformity" as the stoma migrates superiorly.

After prepping and draping, a horizontal or vertical skin incision is made and the subcutaneous fat is removed superficial to the strap muscles. The strap muscles are divided and exposure of the laryngotracheal skeleton is made with lateral retraction of peritracheal soft tissue. The tracheal incision is then planned below the cricoid at the 2nd to 4th tracheal ring. Inspired oxygen is increased and monopolar electrocautery is not planned from this point forward. Non-absorbable monofilament "rescue" or "stay" sutures are placed just off of 
midline on both sides of the planned tracheostomy. These sutures are labeled "left" and "right" and left in place. Prior to the tracheal incision, stomal maturation may be performed using absorbable suture, sewing peristomal skin to tracheal perichondrium in a half-mattress fashion in four quadrants. If desired, the lateral skin edges may also be closed primarily at this stage if a horizontal skin incision was performed.

The tracheal incision is typically made in a vertical fashion between the $2 \mathrm{nd}$ and $3 \mathrm{rd}$ or the $3 \mathrm{rd}$ and 4 th tracheal ring depending on the patient's anatomy. If not already performed, stomal maturation can be accomplished after the tracheal incision, sewing skin to the trachea in a simple interrupted fashion. The length of the tracheal incision should allow the insertion of the tracheostomy tube without any resistance. Trachealis injuries can occur due to excessive force when initially inserting the tracheostomy tube. The stay sutures can be used to elevate the trachea during stomal maturation and guide placement of the tube.

A survey of experts in the field of pediatric otolaryngology agreed upon the necessary surgical steps used to evaluate trainees in their proficiency performing a pediatric tracheostomy $[25 \bullet \cdot]$. Several peer-reviewed surgical videos illustrating the steps of surgery have also been published [26-28].

Debate exists regarding a vertical or horizontal incision of the tracheal cartilage. A 2008 survey study of members of the American Society for Pediatric Otolaryngology (ASPO) [29] demonstrated that $87 \%$ of respondents used a vertical tracheal incision in infants and that fellowship training was associated with more frequent use of this incision. Vertical incisions are supported by a widely cited animal study of postdecannulation tracheal stenosis comparing several techniques [30]. However, others advocate for a superiorly based tracheal flap [31], a horizontal tracheal incision [32] or a window excision [33], all with low rates of post-decannulation stenosis.

Considerations regarding surgical technique and perioperative care were reviewed by the International Pediatric Otolaryngology Group (IPOG) [2••]. IPOG recommends the use of stay sutures in all cases, consideration of stomal maturation, consideration of full airway endoscopy during the same anesthetic, and consideration of flexible tracheoscopy postoperatively to confirm proper tube placement. The tracheal incision technique was not addressed in their review.

\section{Rescue Sutures and Stomal Maturation}

Accidental decannulation of a fresh tracheostomy, i.e., within 5 days of surgery, can be a dangerous complication. The chance of this event is greater in newborns and children, so precautions are taken to prevent decannulation and allow for easy re-insertion. Non-absorbable "rescue" or "stay" sutures are secured on both sides of the tracheal incision at the time of placement. These can be used to elevate the trachea to the surface of the skin and aid in replacing the fresh tracheostomy tube.
Absorbable sutures may also be placed at the time of the tracheostomy to "mature" the skin of the neck to the trachea [34]. Stomal maturation can be performed prior to the tracheal incision or just afterward. A criticism of stomal maturation is the concern for increased risk of persistent tracheocutaneous fistula (TCF) after decannulation. A non-randomized retrospective study [35] comparing stomal maturation to no stomal maturation demonstrated similar rates of TCF regardless of technique. Additionally, there was no difference in mortality or overall complication rates.

\section{Tracheostomy Sizing}

The size of the tracheostomy tube in children is very important. Tracheostomy tubes are labeled according to the size of their inner diameter in millimeters and are generally available in half sizes. Most manufacturers provide both shorter (neonatal) and longer (pediatric) tube lengths. Selecting the proper tracheostomy tube is crucial. A tracheostomy tube that is too small in diameter may be more prone to plugging and fail to deliver adequate tidal volumes, while a tube that is too large may cause injury or irritation of the inner wall of the trachea. A tube that is too short poses a higher risk of decannulaton, while a tube that is too long can irritate the posterior trachea or carina causing a persistent cough. Most children initially require a cuffed tracheostomy to allow for sedated mechanical ventilation during the healing period. Once patients wean from mechanical ventilation, the cuff is deflated and eventually the tube can be exchanged for an uncuffed model that allows for more airflow through the upper airway with the recovery of voice.

The size of cuffed endotracheal tubes in children is determined using Motoyama's formula (3.5 + patient age/4) [36]. This formula may assist in approximate tracheostomy tube sizing in children although patient factors can affect the formula's accuracy [37]. For this reason, many surgeons advocate for full airway endoscopy prior to the initial skin tracheostomy incision. For children with special anatomic needs, some brands offer adjustable length, or even custom length tracheostomy tubes of various sizes.

Additional flexible tubing can extend from the tube's ventilation port in some tracheostomy models to help reduce post-operative skin injury and increase tolerance of the ventilation circuit. This is especially true in neonates. However, extended tubes are less preferred in agile children due to the risk of accidental removal by an intolerant patient. Children might begin with flexible extended tubes but progress to straight and uncuffed tubes once mechanical ventilation is no longer needed. For an exhaustive review of pediatric tracheostomy tube options and sizes, we refer the reader to another review specific to this topic by Tweedie et al. [38] 


\section{Bedside Tracheostomy}

While there have been recent trends toward the use of bedside, percutaneous, or dilational tracheostomy in the adult intensive care setting, these techniques have not carried over to the pediatric population. A case series [39] comparing operating room to bedside PICU tracheostomies suggested a reduced cost and similar complication risk in bedside procedures. Roughly $75 \%$ of the patients were younger than 2 years. A more recent review of bedside tracheostomy [40] included 20 children in a series of 200 patients, but outcomes specific to children were not reported.

Extracorporeal membrane oxygenation (ECMO) and highfrequency oscillatory ventilation may complicate patient transportation out of the intensive care unit. These patients are both candidates for bedside tracheostomy and stoma maturation before the tracheal incision. Nine cases of bedside tracheostomy in patients receiving ECMO were recently reported with a mix of open, percutaneous, and combined approaches. Anticoagulation was held perioperatively in these patients [41].

\section{Complications and Aftercare}

Common complications of pediatric tracheostomy include mucus plugging, pressure injuries, bleeding, granulation tissue, and tracheocutaneous fistula (TCF). Rarer complications include subcutaneous emphysema, pneumomediastinum, tracheoinnominate fistula (TIF), subglottic and/or tracheal stenosis, and esophageal injury. In a recent systematic review [17•], all complications appear to be decreasing in incidence which is thought to be related to improved surgical technique and performance by a higher degree of subspecialists.

\section{Wound Care}

Peristomal skin breakdown and pressure ulcers are an important concern in the perioperative period in pediatric tracheostomy tube placement. Mobility, secretions, and poor wound healing appear to contribute to a higher rate of this complication in the neonatal period. In addition to patient morbidity, family anxiety, and elevated resource utilization, this complication can also impact hospital reimbursement [42].

Formalized multidisciplinary teams can reduce the incidence of tube-related pressure ulcers in pediatric patients [43]. Despite these efforts, pressure ulcers occur nearly $10 \%$ of all tracheostomies. Maltodextrin gel and/or silver alginate sponges has been demonstrated to be effective in improving stoma and wound breakdown in these patients [44]. This can be used as a preventive measure or after the development of injury.
Twill ties are useful in preventing accidental decannulation of children with tracheostomies. However, they also have a higher rate of associated neck pressure ulcers. They have a smaller width and have a tendency to retain secretions compared to hook-and-loop cushioned ties. A randomized controlled trial [45] in 57 patients demonstrated no significant difference with respect to accidental decannulation or skin injury between traditional twill versus cushioned ties. Another study [46] of 109 patients demonstrated a higher incidence of skin irritation and breakdown using twill ties but had no accidental decannulations in either group. These data seem to indicate that twill ties confer no benefit over hook-and-look ties and may increase the risk of skin irritation and breakdown.

\section{Granulation Tissue}

Granulation tissue is the result of persistent irritation of the skin and airway by the tracheostomy tube at the stoma site. This tissue is friable and bleeds easily causing increased caregiver concern and anxiety and potentially making tracheostomy changes more difficult. As granulation tissue matures, dense scar tissue can form. Granulation of the peristomal skin can be treated topically with silver nitrate in the clinic setting. However, granulation tissue in the airway requires surgical intervention. The optimal timing of routine endoscopic surveillance for asymptomatic tracheostomy patients is unclear.

Two retrospective studies $[47,48]$ of routine surveillance airway endoscopy after tracheostomy demonstrated that airway lesions requiring intervention were common (30-40\%). Of those who were asymptomatic, $15 \%$ had airway lesions that necessitated intervention, most commonly removal of granulation tissue. Granulation tissue was more common in patients with cardiopulmonary indications for their tracheostomy. This may be due to aberrant positioning caused by the ventilator circuit or from dynamic airway collapse onto the tube itself.

Neither study described the state of the patient's tracheostomy cuff status (inflated/deflated), speaking valve tolerance, or voice quality at the time of endoscopy. These variables could reveal information about the suprastomal trachea and subglottis to help direct surgeons in timing their surveillance.

Although most granulation tissue occurs at the stoma, granulation tissue development in the distal trachea from irritation by the tip of the tracheostomy tube or excessively deep suctioning is of much greater concern, as this can cause tube obstruction. In such cases, formal airway evaluation in the operating room is often indicated to ensure that the size and shape of the tube are appropriate for the patient's anatomy. Typically, patients respond to changing the length of the tracheostomy tube, re-educating the depth of suctioning, and topical medications (antibiotic and steroid) via the tracheostomy tube. 


\section{Subglottic/Tracheal Stenosis}

While tracheostomy can be indicated for airway stenosis, it can also contribute to the problem by weakening the surrounding tracheal cartilage. Suprastomal collapse may be a cause for late failure of decannulation. Several treatment options have been explored for this phenomenon, including anterior wall tracheal resection [49], costal cartilage grafting [50], and external stenting with bioabsorbable miniplates [51,52].

\section{Tracheocutaneous Fistula}

Tracheocutaneous fistula (TCF) is a late complication of tracheostomy which has been found to be much more common with a longer period of tracheostomy prior to decannulation [53]. There appears to be no increased risk of TCF when stomal maturation sutures are used. Treatment of TCF includes airway endoscopy to ensure the patient is not dependent on the fistula for ventilation, followed by excision with either primary closure or healing by secondary intention.

\section{Tracheoinnominate Fistula}

Tracheoinnominate fistula (TIF) is a potentially lethal, fortunately rare, complication. A systematic review of case reports and case series [54] in the pediatric population demonstrated that the mean time to development of a TIF was 397 days. Interestingly, the mean was longer in reports published after the year 2000 than in those published earlier (655 days vs 104 days). A sentinel, i.e., early warning, bleeding event preceded more significant bleeding events by an average of about $24 \mathrm{~h}$, range 5-50 h. The majority of definitive management strategies in the review were treated with open surgical approaches, though some were treated endovascularly. The overall mortality rate from this complication was nearly $40 \%$ in this series.

\section{Infection, Pneumomediastinum, and Pneumothorax}

Local wound infection may occur but is usually self-limited. This is typically associated with poor secretion management which leads to faster degradation of the maturation sutures. If the maturation sutures fail too early, access to the cervical neck and chest appears. If this is noticed quickly, bedside wound care with packing will prevent more serious complications. However, stoma healing will be delayed due to secondary healing.

If air escapes from the trachea and remains trapped beneath the skin, pneumomediastinum and/or pneumothorax can occur. For this reason, a post-operative chest $\mathrm{x}$-ray may be performed to identify these complications and serve as a baseline. However, a review [55] of 421 patients who underwent routine chest $\mathrm{x}$-ray after tracheostomy identified only 3 cases of air tracking complications, all of whom were clinically suspected before the $\mathrm{x}$-ray.

Changes in tracheal secretion consistency, odor, or frequency often lead to microbiologic analyses. Practitioners should keep in mind that bacterial colonization of indwelling tracheostomy tubes is common [56] but may be of questionable clinical significance [57].

\section{Tracheostomy Tube Changes and Supplies}

In the first few days following tracheostomy, the peristomal skin heals to the tracheal mucosa to establish a stable tract. The timing of this stability is not widely accepted, but most IPOG members [2••] report waiting until 5 to 7 days have passed before changing out the initial tracheostomy tube. Others have waited as little as 2 days for this initial tube change to facilitate early transfer out of PICU, with good results in 26 patients [58].

The initial tube change is usually performed by the surgical team to confirm that the healing process has taken place and in case of difficulty if it has not. Thereafter, hospital nursing or respiratory staff and (eventually) caregivers can safely assume this responsibility.

In both inpatient and outpatient post-operative settings, multiple supplies should be readily available in the case of mucus plug or accidental decannulation. At our institution, a supply bag (i.e., "Trach Go Bag") provides a place to store these supplies for nursing staff transporting the patient and for families at home. A retrospective study demonstrated a nonsignificant trend in reduction of tracheostomy-related adverse events with the institution of a Go Bag policy for all tracheostomy patients both upon admission and at discharge [59].

\section{Decannulation}

Compared to their adult counterparts, most pediatric patients are less able to report respiratory difficulty due either to age or to developmental delays. Additionally, the consequences of failed decannulation are likely higher in pediatric patients due to communication, developmental barriers, and smaller anatomy.

According to the American Association of OtolaryngologyHead and Neck Surgery (AAO-HNS) clinical consensus guidelines on tracheostomy care [1・•], all of the following are necessary criteria for safe pediatric decannulation:

- Graduation from regular use of mechanical ventilation (possibly allowing for occasional backsliding during acute illness), absence of recent known aspiration events,

- Completion of an endoscopic airway assessment confirming the absence of upper airway pathology that could be masked by the tracheostomy tube (including 
awake flexible laryngoscopy to assess vocal fold movement), and

- Safe daytime capping of the tracheostomy tube for several weeks.

Additional optional steps may include:

- Successful weaning from supplemental oxygen,

- Interval downsizing of the existing tracheostomy, tolerance of a Passy Muir speaking valve (PMV),

- Performance of a drug-induced sleep endoscopy, and

- The performance of a capped or decannulated polysomnography (PSG).

However, there is little agreement regarding the safest and most cost-effective process to confirm a child is ready for decannulation.

Recent publications that analyzed the success of decannulation protocols in various patient populations $\left[60^{\bullet}\right.$, $61 \bullet, 62 \cdot, 63 \bullet, 64 \bullet, 65 \bullet, 66 \bullet, 67 \bullet]$ are listed in Table 2. All studies were retrospective. The rate of successful decannulation reported is extremely variable $(0-45 \%)$ owing partly to differences in clinical practice, patient population, and individual protocols. There was also significant disagreement in how "failure" was defined. While most would define a failure as re-insertion of a tracheostomy tube after removal, some groups obtained PSG with a capped tube, while others obtained it immediately upon decannulation. If the same patient failed PSG in both protocols, this would be considered a protocol success in the first case but a failure in the second case.

Only one study $[61 \bullet]$ reported a sufficient number of failed decannulations to analyze the risk factors for failure. These included a history of prematurity, dysphagia with a history of gastrostomy tube placement, craniofacial or genetic syndromes, hydrocephalus, BPD, and the decision to decannulate primarily based on the parental expectation of success. Unfortunately, the authors' criteria used for these risk factors are not further described.

Polysomnography parameters predicting decannulation failure were reported by two studies $\left[60^{\bullet}, 68^{\bullet}\right]$. The studies demonstrated agreement in their findings, with decannulation failure predicted by overall apnea-hypopnea index (AHI) (3.35 and 1.70 for the successful decannulation groups versus 18.5 and 12.8 for the unsuccessful decannulation groups) and mean oxygen saturation nadir $(87.58 \%$ and $89 \%$ for the successful groups versus $82 \%$ and $78.57 \%$ for the unsuccessful groups). Given that these findings were retrospective, the actual risk of failed decannulation when these variables are unfavorable is likely even higher than reported.

Two papers are notable for their $0 \%$ failure rate, both in inpatient rehabilitation. Each study reported on institutional protocols using either airway endoscopy in every patient with selective PSG [64-] or capped PSG in every patient with selective endoscopy [66॰]. The success rate in this population underlines the advantages of being able to trial downsizing, capping, and decannulation in an inpatient setting with the option for continuous pulse oximetry as opposed to doing so on a primarily outpatient basis. It should be noted that all of these patients had neurologic comorbidities, and the patients in these studies tended to be older: in one study, the average age was 13.6 years, and in the other, the median age was 8.7 years.

While some additional studies $\left[10^{\bullet}, 18 \bullet, 69\right]$ have evaluated the likelihood of decannulation in institutional or national populations from the time of tracheostomy, these studies did not track failed decannulation attempts, so the risk of decannulation failure was not evaluable. Favorable predictors for decannulation include older age at the time of tracheostomy and those with airway obstruction as an indication for tracheostomy. Although neurologic comorbidities may be unfavorable for decannulation, acquired neurologic disease was demonstrated in one of these studies to be favorable.

\section{Discussion}

Tracheostomy is an important procedure that can benefit many patients in intensive care. Recently published studies demonstrate a trend toward consideration for earlier tracheostomy, which can reduce the length of stay. However, a lower risk of mortality with an earlier tracheostomy has not been established. While tracheostomyspecific mortality rates are low, patients with significant comorbidities carry a significantly higher mortality rate. There is disagreement in the recently published literature regarding age as an independent risk factor for mortality, which may be due to differences in populations across different studies and institutions.

The overwhelming majority of pediatric tracheostomies are still performed in the operating room. However, some surgeons have performed the procedure at the bedside in appropriately selected patients. The surgical technique is otherwise relatively standardized with some minor variations, including the use of stomal maturation sutures, vertical tracheal incision, and performance of pre- and/or post-operative airway endoscopy. Many would consider post-operative chest $\mathrm{x}$-ray the standard of care, though its utility has been questioned.

Despite multiple recent publications on decannulation protocols, there remains little agreement in the literature regarding the most efficient method to confirm patients are ready for tracheostomy tube removal, involving the use of PSG, airway endoscopy, tube downsizing, and both capping trials and inpatient post-decannulation monitoring of various lengths. In older children, safe decannulation 
Table 2 Recent publications, pediatric decannulation protocols

\begin{tabular}{|c|c|c|c|c|c|c|}
\hline $\begin{array}{l}\text { Primary author, } \\
\text { year }\end{array}$ & Patient population & $N$ & $\begin{array}{l}\text { Standardized decannulation } \\
\text { protocol }\end{array}$ & $\begin{array}{l}\text { Inpatient nights } \\
\text { required } \\
\text { (if specified) }\end{array}$ & $\begin{array}{l}\text { Failure rate } \\
\text { (first } \\
\text { decannulation, } \\
\text { if multiple) }\end{array}$ & Risk factors for failure \\
\hline $\begin{array}{l}\text { Cristea, } 2016 \\
{\left[60^{\bullet}\right]}\end{array}$ & $<18 \mathrm{y} / \mathrm{o}$ & 210 & $\begin{array}{l}\text { Admission MLB or sleep } \\
\text { endoscopy; decannulation in sleep } \\
\text { lab with immediate PSG; formal } \\
\text { PSG }\end{array}$ & 1 & $20.4 \%$ & \\
\hline Lee, 2016 [68•] & $<18$ y/o & 30 & $\begin{array}{l}\text { Downsize to 3-mm tube; awake } \\
\text { capping; admission with } \\
\text { overnight pulse oximetry; formal } \\
\text { capped PSG; decannulation; } \\
\text { discharge }\end{array}$ & 2 & $13.3 \%$ & \\
\hline $\begin{array}{l}\text { Beaton, } 2016 \\
{[67 \cdot]}\end{array}$ & $<18 \mathrm{y} / \mathrm{o}$ & 45 & $\begin{array}{l}\text { MLB; trach tube downsize; trach } \\
\text { tube capping; decannulation; } \\
\text { overnight observation; discharge }\end{array}$ & 4 & $44.5 \%$ & - \\
\hline $\begin{array}{l}\text { Banyopadhyay, } \\
2016[61 \cdot]\end{array}$ & $<18 \mathrm{y} / \mathrm{o}$ & 189 & $\begin{array}{l}\text { MLB with temporary decannulation; } \\
\text { admission with decannulation and } \\
\text { immediate PSG; overnight PSG; } \\
\text { discharge }\end{array}$ & 1 & $22.2 \%$ & $\begin{array}{l}\text { Prematurity, decannulation } \\
\text { based on parental } \\
\text { expectations of success, } \\
\text { dysphagia, } \\
\text { craniofacial/genetic } \\
\text { comorbidities, } \\
\text { hydrocephalus, BPD }\end{array}$ \\
\hline $\begin{array}{l}\text { Wirtz, } 2016 \\
{[62 \cdot]}\end{array}$ & $<18 \mathrm{y} / \mathrm{o}$ & 35 & $\begin{array}{l}\text { Sleep endoscopy } \pm \text { MLB with } \\
\text { temporary decannulation; PICU } \\
\text { admission with decannulation; } \\
\text { discharge }\end{array}$ & $1+$ & $5.7 \%$ & - \\
\hline $\begin{array}{l}\text { Maslan, } 2017 \\
{[63 \cdot]}\end{array}$ & $<18 \mathrm{y} / \mathrm{o}$ & 46 & $\begin{array}{l}\text { No fixed protocol, most underwent } \\
\text { MLB and PSG }\end{array}$ & Variable & $2.1 \%$ & - \\
\hline $\begin{array}{l}\text { Pozzi, } 2017 \\
\quad[64 \bullet]\end{array}$ & $\begin{array}{l}<18 \mathrm{y} / \mathrm{o} \text { in inpatient } \\
\text { rehab }\end{array}$ & 68 & $\begin{array}{l}\text { Inpatient capping trials with } \\
\text { continuous pulse oximetry; } \\
\text { fiberoptic laryngoscopy; selective } \\
\text { PSG only }\end{array}$ & $\begin{array}{l}\text { N/A (inpatient } \\
\text { for rehab) }\end{array}$ & $0 \%$ & \\
\hline $\begin{array}{l}\text { Seligman, } 2019 \\
{\left[65^{\bullet}\right]}\end{array}$ & $0-5 \mathrm{y} / 0$ & 26 & $\begin{array}{l}\text { MLB; change to fenestrated trach } \\
\text { tube when awake; inpatient } \\
\text { overnight pulse oximetry; } \\
\text { decannulation; half-day pulse } \\
\text { oximetry; discharge }\end{array}$ & 1 & $15.3 \%$ & - \\
\hline $\begin{array}{l}\text { Morrow, } 2019 \\
{[66 \bullet]}\end{array}$ & $\begin{array}{l}0-21 \text { y/o with brain } \\
\text { or spinal cord } \\
\text { injuries who } \\
\text { underwent PSG } \\
\text { for decannulation }\end{array}$ & 38 & $\begin{array}{l}\text { Capped PSG during inpatient stay; } \\
\text { selective airway endoscopy }\end{array}$ & $\begin{array}{l}\text { N/A (inpatient } \\
\text { for rehab) }\end{array}$ & $0 \%$ & - \\
\hline
\end{tabular}

Summary of decannulation studies published since 2016. N, number of patients in the cited study; $y / o$, years old; MLB, microlaryngoscopy and bronchoscopy; $P S G$, polysomnogram; $B P D$, bronchopulmonary dysplasia; N/A, not applicable

may be possible without PSG or endoscopy if the patient remains in the inpatient setting for post-decannulation surveillance. This should be an area of focus for future research.

\section{Conclusion}

A pediatric tracheostomy is an important tool for the care of critically ill patients who are otherwise unable to wean from ventilator support. Tracheostomy complications can be reduced with proper surgical technique and astute postoperative management. Controversies in tracheostomy decannulation warrant future research and stratification of this heterogeneous population.

\section{Declarations}

Conflict of Interest Gresham T. Richter is a Board Member of and has an equity stake in GDT Innovations, LLC. The other authors declare that they have no conflict of interest. 
Human and Animal Rights and Informed Consent This article does not contain any studies with human or animal subjects performed by any of the authors.

\section{References}

Papers of particular interest, published recently, have been highlighted as:

- Of importance

•- Of major importance

1.• Mitchell RB, Hussey HM, Setzen G, et al. Clinical consensus statement. Otolaryngol-Head Neck Surg. 2013;148(1):6-20. https://doi. org/10.1177/0194599812460376 https://journals.sagepub.com/doi/ full/10.1177/0194599812460376. This clinical consensus statement summarizes the American Academy or Otolaryngology-Head and Neck Surgery recommendations regarding tracheostomy in both adults and children.

2.• Strychowsky JE, Albert D, Chan K, et al. International pediatric otolaryngology group (IPOG) consensus recommendations: routine peri-operative pediatric tracheotomy care. Int J Pediatr Otorhinolaryngol. 2016;86:250-5. https://doi.org/10.1016/j.ijporl. 2016.03.029 https://search.datacite.org/works/10.1016/j.ijporl. 2016.03.029. This survey describes common practice regarding peri-operative care of the patient with a tracheostomy tube among pediatric otolaryngologists.

3. Friesen TL, Zamora SM, Rahmanian R, Bundogji N, Brigger MT. Predictors of pediatric tracheostomy outcomes in the united states. Otolaryngol-Head Neck Surg. 2020;163:19459982091762194599820917620. https://search.proquest.com/docview/ 2393660977. https://doi.org/10.1177/0194599820917620. This retrospective study's findings regarding post-tracheostomy mortality are summarized in Table 1.

4. Swift AC, Rogers JH. The changing indications for tracheostomy in children. J Laryngol Otol. 1987;101(12):1258-62.

5. Lui K, Lee SK, Kusuda S, et al. Trends in outcomes for neonates born very preterm and very low birth weight in 11 high-income countries. J Pediatrics. 2019;215:32-40.e14. https://search. datacite.org/works/10.1016/j.jpeds.2019.08.020. https://doi.org/ 10.1016/j.jpeds.2019.08.020.

6. Hopkins C, Whetstone S, Foster T, Blaney S, Morrison G. The impact of paediatric tracheostomy on both patient and parent. Int J Pediatric Otorhinolaryngol. 2008;73(1):15-20. https://www. clinicalkey.es/playcontent/1-s2.0-S0165587608004400. https:// doi.org/10.1016/j.ijporl.2008.09.010.

7. Amar-Dolan LG, Horn MH, O’Connell B, Parsons SK, Roussin CJ, Weinstock PH, et al. "This is how hard it is": family experience of hospital-to-home transition with a tracheostomy. Ann Am Thoracic Soc. 2020;17(7):860-8. https://www.ncbi.nlm.nih.gov/pubmed/ 32267725. https://doi.org/10.1513/AnnalsATS.201910-780OC.

8. October TW, Jones AH, Greenlick Michals H, Hebert LM, Jiang J, Wang J. Parental conflict, regret, and short-term impact on quality of life in tracheostomy decision-making. Pediatric Crit Care Med. 2020;21(2):136-42. https://www.ncbi.nlm.nih.gov/pubmed/ 31568244. https://doi.org/10.1097/PCC.0000000000002109.

9. Funamura JL, Yuen S, Kawai K, Gergin O, Adil E, Rahbar R, et al. Characterizing mortality in pediatric tracheostomy patients. The Laryngoscope. 2017;127(7):1701-6. https://search.datacite.org/ works/10.1002/lary.26361. https://doi.org/10.1002/lary.26361. This retrospective study's findings regarding posttracheostomy mortality are summarized in Table 1.
10. Tsuboi N, Ide K, Nishimura N, Nakagawa S, Morimoto N. Pediatric tracheostomy: survival and long-term outcomes. Int $\mathrm{J}$ Pediatric Otorhinolaryngol. 2016;89:81-5. https://www. clinicalkey.es/playcontent/1-s2.0-S0165587616302452. https:// doi.org/10.1016/j.ijporl.2016.07.033. This retrospective study's findings regarding post-tracheostomy mortality are summarized in Table 1.

11. Gergin O, Adil EA, Kawai K, Watters K, Moritz E, Rahbar R. Indications of pediatric tracheostomy over the last 30 years : Has anything changed? Int J Pediatric Otorhinolaryngol. 2016;87:144 7. https://www.clinicalkey.es/playcontent/1-s2.0 S0165587616301598. https://doi.org/10.1016/j.ijporl.2016.06.018.

12. Prodhan P, Agarwal A, ElHassan NO, et al. Tracheostomy among infants with hypoplastic left heart syndrome undergoing cardiac operations: a multicenter analysis. Ann Thoracic Surg. 2017;103(4):1308-14. https://search.datacite.org/works/10.1016/j. athoracsur.2016.09.016. https://doi.org/10.1016/j.athoracsur.2016. 09.016. This retrospective study's findings regarding posttracheostomy mortality are summarized in Table 1.

13. Marshall V, Holt F, Crowe S. Tracheostomy as a comfort measure in children with life-limiting conditions. J Palliat care. 2017;32(34):89-91. https://journals.sagepub.com/doi/full/10.1177/ 0825859717740064. https://doi.org/10.1177/0825859717740064.

14. Finkel RS, Mercuri E, Darras BT, Connolly AM, Kuntz NL, Kirschner J, et al. Nusinersen versus sham control in infantileonset spinal muscular atrophy. N Engl J Med. 2017;377(18): 1723-32.

15. Mercuri E, Darras BT, Chiriboga CA, Day JW, Campbell C, Connolly AM, et al. Original article. N Engl J Med. 2018;378(7): 625-35.

16. Watters K, O’Neill M, Zhu H, Graham RJ, Hall M, Berry J. Twoyear mortality, complications, and healthcare use in children with medicaid following tracheostomy. The Laryngoscope. 2016;126(11):2611-7. https://search.datacite.org/works/10.1002/ lary.25972. https://doi.org/10.1002/lary.25972. This retrospective study's findings regarding post-tracheostomy mortality are summarized in Table 1.

17. Dal'Astra APL, Quirino AV. Caixêta, Juliana Alves de Sousa, Avelino MAG. Tracheostomy in childhood: review of the literature on complications and mortality over the last three decades. Braz J Otorhinolaryngol. 2017;83(2):207-14. https://search.datacite.org/ works/10.1016/j.bjorl.2016.04.005. https://doi.org/10.1016/j.bjorl. 2016.04.005. This met-analysis's findings regarding posttracheostomy mortality from $\mathbf{2 0 0 5 - 2 0 1 4}$ are summarized in Table 1.

18. McPherson ML, Shekerdemian L, Goldsworthy M, et al. A decade of pediatric tracheostomies: indications, outcomes, and long-term prognosis. Pediatric Pulmonol. 2017;52(7):946-53. https:// onlinelibrary.wiley.com/doi/abs/10.1002/ppul.23657. https://doi. org/10.1002/ppul.23657. This retrospective study's findings regarding post-tracheostomy mortality are summarized in Table 1.

19. Rizzi CJ, Amin JD, Isaiah A, Valdez TA, Jeyakumar A, Smart SE, et al. Tracheostomy for severe pediatric obstructive sleep apnea: indications and outcomes. Otolaryngol-Head Neck Surg. 2017;157(2):309-13. https://search.datacite.org/works/10.1177/ 0194599817702369. https://doi.org/10.1177/0194599817702369. This retrospective study's findings regarding posttracheostomy mortality are summarized in Table 1.

20. Rawal RB, Farquhar DR, Kilpatrick LA, Drake AF, Zdanski CJ. Considering a weight criterion for neonatal tracheostomy: an analysis of the ACS NSQIP-P. The Laryngoscope. 2019;129(2):500-5. https://onlinelibrary.wiley.com/doi/abs/10.1002/lary.27272. https://doi.org/10.1002/lary.27272. This retrospective study's findings regarding post-tracheostomy mortality are summarized in Table 1. 
21. Han SM, Watters KF, Hong CR, Edwards EM, Knell J, Morrow $\mathrm{KA}$, et al. Tracheostomy in very low birth weight infants: a prospective multicenter study. Pediatrics (Evanston). 2020;145(3): e20192371. https://www.ncbi.nlm.nih.gov/pubmed/32098788. https://doi.org/10.1542/peds.2019-2371. This prospective study's findings regarding post-tracheostomy mortality are summarized in Table 1.

22. Meyer-Macaulay CB, Dayre McNally J, O’Hearn K, Lynne Katz S, Thébaud B, Vaccani JP, et al. Factors impacting physician recommendation for tracheostomy placement in pediatric prolonged mechanical ventilation: a cross-sectional survey on stated practice. Pediatric Crit Care Med. 2019;20(9):e423-31. https://www.ncbi. nlm.nih.gov/pubmed/31246744. https://doi.org/10.1097/PCC. 0000000000002046.

23. Principi T, Morrison G, Matsui D, et al. Elective tracheostomy in mechanically ventilated children in canada. Intensive Care Med. 2008;34(8):1498-502. https://www.ncbi.nlm.nih.gov/pubmed/ 18418569. https://doi.org/10.1007/s00134-008-1104-x.

24. Abdelaal Ahmed Mahmoud M. Alkhatip, Ahmed, Younis M, Jamshidi N, et al. Timing of tracheostomy in pediatric patients: a systematic review and meta-analysis. Crit Care Med. 2020;48(2): 233-40. http://ovidsp.ovid.com/ovidweb.cgi?T=JS\&NEWS= $\mathrm{n} \& \mathrm{CSC}=\mathrm{Y} \& \mathrm{PAGE}=$ fulltext $\& \mathrm{D}=\mathrm{ovft} \& \mathrm{AN}=00003246$ 202002000-00014. https://doi.org/10.1097/CCM. 0000000000004114.

25.• Propst EJ, Wolter NE, Ishman SL, et al. Competency-based assessment tool for pediatric tracheotomy: international modified Delphi consensus. Laryngoscope. 2020;130:2700-7 This survey study of experts in pediatric tracheostomy laid out critical operative steps, creating an assessment tool useful for evaluating surgical trainees in their proficiency with the procedure.

26. Lau C, Stone B, DeHart A, Kubala M, Richter G. Pediatric tracheostomy. https://www.csurgeries.com/video/pediatrictracheostomy/\#toggle-id-12. Updated 2019. Accessed 8/29/, 2020.

27. Vijayasekaran S, Uwiera R, Smith A, Herbert H, Uwiera T. Pediatric tracheostomy with stomal maturation sutures. https:// www.csurgeries.com/video/pediatric-tracheostomy-maturationsutures/\#toggle-id-1. Updated 2020. Accessed 8/29/, 2020.

28. Marrugo Pardo GE, Parra Charris J. How to perform a tracheostomy on an infant. https://www.csurgeries.com/video/performtracheostomy-infant/. Updated 2020. Accessed 8/29/, 2020.

29. Ruggiero FP, Carr MM. Infant tracheotomy: results of a survey regarding technique. Arch Otolaryngol-Head Neck Surg. 2008;134(3):263-7. https://doi.org/10.1001/archoto.2007.24.

30. Fry TL, Jones RO, Fischer ND, Pillsbury HC. Comparisons of tracheostomy incisions in a pediatric model. Ann Otol, Rhinol Laryngol. 1985;94(5):450-3.

31. Rhee C, Miller FR, Tucker HM, Eliachar I. The superiorly based flap long-term tracheostomy in pediatric patients. Am J Otolaryngol. 1996;17(4):251-6. https://doi.org/10.1016/S01960709(96)90090-3.

32. Song JJ, Choi IJ, Chang H, Kim DW, Chang HW, Park GH, et al. Pediatric tracheostomy revisited: a nine-year experience using horizontal intercartilaginous incision. Laryngoscope. 2015;125:48592.

33. Syed KA, Naina P, Pokharel A, John M, Varghese AM. Paediatric tracheostomy: a modified technique and its outcomes, results from a south indian tertiary care. Int J Pediatric Otorhinolaryngol. 2019;118:6-10.

34. Park JY, Suskind DL, Muntz HR, Prater D, Lusk RP. Maturation of the pediatric tracheostomy stoma: effect on complications. Ann Otol, Rhinol Laryngol. 1999;108(12):1115-9. https://journals. sagepub.com/doi/full/10.1177/000348949910801204. https://doi. org/10.1177/000348949910801204.

35. Levi JR, Topf MC, Mostovych NK, Yoo E, Barth PC, Shah UK. Stomal maturation does not increase the rate of tracheocutaneous fistulas. The Laryngoscope. 2016;126(10):2395-8. https:// onlinelibrary.wiley.com/doi/abs/10.1002/lary.26225. https://doi. org/10.1002/lary.26225.

36. Motoyama EK. Endotracheal intubation. In: Smith's anesthesia for infants and children. St. Louis, MO: CV Mosby; 1990. p. 269-75.

37. Naina P, Syed KA, Irodi A, John M, Varghese AM. Pediatric tracheal dimensions on computed tomography and its correlation with tracheostomy tube sizes. The Laryngoscope. 2019;130(5):1316-21. https://search.datacite.org/works/10.1002/lary.28141. https://doi. org/10.1002/lary.28141.

38. Tweedie DJ, Skilbeck CJ, Cochrane LA, Cooke J, Wyatt ME. Choosing a paediatric tracheostomy tube: an update on current practice. J Laryngol Otol. 2007;122(2):161-9. https://doi.org/10. 1017/S0022215107007190.

39. Klotz DA, Hengerer AS. Safety of pediatric bedside tracheostomy in the intensive care unit. Arch Otolaryngol-Head Neck Surg. 2001;127(8):950-5. https://doi.org/10.1001/archotol.127.8.950.

40. Sinha V, Jha SG, Umesh ST, Chaudhari NP, Parmar BD, Patel RS. Bedside tracheostomy: Our experience in a tertiary care hospital. Indian J Otolaryngol, Head, Neck Surg. 2020:1-4. https://search. proquest.com/docview/2437119096. https://doi.org/10.1007/ s12070-020-01976-w.

41. Schwartz SP, Bonadonna D, Hartwig MG, Cheifetz IM. Bedside tracheostomy on pediatric ICU subjects supported by extracorporeal membrane oxygenation. Respiratory Care. 2017;62(11):144755. https://search.datacite.org/works/10.4187/respcare.05442. https://doi.org/10.4187/respcare.05442.

42. Quick safety 43: Managing medical device-related pressure injuries. https://www.jointcommission.org/resources/news-andmultimedia/newsletters/newsletters/quick-safety/quick-safety-43managing-medical-devicerelated-pressure-injuries. Accessed September 1st, 2020.

43. McEvoy TP, Seim NB, Aljasser A, et al. Prevention of postoperative pediatric tracheotomy wounds: a multidisciplinary team approach. Int J Pediatric Otorhinolaryngol. 2017;97:235-9. https:// www.clinicalkey.es/playcontent/1-s2.0-S0165587617301398. https://doi.org/10.1016/j.ijporl.2017.03.037.

44. Hartzell LD, Havens TN, Odom BH, Stillman TG, Boswell JL, Bower CM, et al. Enhanced tracheostomy wound healing using maltodextrin and silver alginate compounds in pediatrics: a pilot study. Respiratory Care. 2014;59(12):1857-62. https://www.ncbi. nlm.nih.gov/pubmed/25096405. https://doi.org/10.4187/respcare. 02822

45. Hart CK, Tawfik KO, Meinzen-Derr J, Prosser JD, Brumbaugh C, Myer A, et al. A randomized controlled trial of Velcro versus standard twill ties following pediatric tracheotomy. The Laryngoscope. 2017;127(9):1996-2001. https://onlinelibrary.wiley.com/doi/abs/ 10.1002/lary.26608. https://doi.org/10.1002/lary.26608.

46. Bitners AC, Burton WB, Yang CJ. Retrospective comparison of Velcro ${ }^{\circledR}$ and twill tie outcomes following pediatric tracheotomy. Int J Pediatric Otorhinolaryngol. 2019;116:192-5. https://search. datacite.org/works/10.1016/j.ijporl.2018.10.022. https://doi.org/ 10.1016/j.ijporl.2018.10.022.

47. Gergin O, Adil E, Kawai K, Watters K, Moritz E, Rahbar R. Routine airway surveillance in pediatric tracheostomy patients. Int J Pediatric Otorhinolaryngol. 2017;97:1-4. https://search.datacite. org/works/10.1016/j.ijporl.2017.03.020. https://doi.org/10.1016/j. ijporl.2017.03.020.

48. Liu CC, Soares JJ, Elder L, Hill L, Abts M, Bonilla-Velez J, et al. Surveillance endoscopy after tracheostomy placement in children: findings and interventions. The Laryngoscope. 2019;130(5):132732. https://search.datacite.org/works/10.1002/lary.28247. https:// doi.org/10.1002/lary.28247.

49. Tawfik A, Ebada HA, El-Fattah AMA, Kamal E. Surgical management of suprastomal tracheal collapse in children. Int J Pediatric Otorhinolaryngol. 2019;118:188-91. https://search.datacite.org/ 
works/10.1016/j.ijporl.2019.01.008. https://doi.org/10.1016/j. ijporl.2019.01.008.

50. Antón-Pacheco JL, Villafruela M, López M, García G, Luna C, Martínez A. Surgical management of severe suprastomal cricotracheal collapse complicating pediatric tracheostomy. Int J Pediatric Otorhinolaryngol. 2007;72(2):179-83. https://www. clinicalkey.es/playcontent/1-s2.0-S0165587607004570. https:// doi.org/10.1016/j.ijporl.2007.10.001.

51. Jayawardena AD, Burks CA, Hartnick CJ. Bioabsorbable microplates as an external stent for suprastomal collapse: a retrospective review. Laryngoscope. 2020((Online ahead of print:1-4.

52. Bowe SN, Colaianni CA, Hartnick CJ. Management of severe suprastomal collapse with bioabsorbable microplates. Laryngoscope. 2017;127:2823-6.

53. Ha T, Goyal M, Ongkasuwan J. Duration of tracheostomy dependence and development of tracheocutaneous fistula in children. The Laryngoscope. 2017;127(12):2709-12. https://onlinelibrary.wiley. com/doi/abs/10.1002/lary.26718. https://doi.org/10.1002/lary. 26718.

54. Lee DJ, Yang W, Propst EJ, Rosenblatt SD, Hseu A, Wolter NE. Tracheo-innominate fistula in children: a systematic review of literature. The Laryngoscope. 2019;130(1):217-24. https://search. datacite.org/works/10.1002/lary.27765. https://doi.org/10.1002/ lary.27765.

55. Genther DJ, Thorne MC. Utility of routine postoperative chest radiography in pediatric tracheostomy. Int J Pediatric Otorhinolaryngol. 2010;74(12):1397-400. https://www. clinicalkey.es/playcontent/1-s2.0-S0165587610004313. https:// doi.org/10.1016/j.ijporl.2010.09.017.

56. Russell CJ, Simon TD, Neely MN. Development of chronic pseudomonas aeruginosa-positive respiratory cultures in children with tracheostomy. Lung. 2019;197(6):811-7. https://search.datacite. org/works/10.1007/s00408-019-00285-6. https://doi.org/10.1007/ s00408-019-00285-6.

57. Espahbodi M, Kallenbach S, Huang C, Chun RH, McCormick ME. Significance of positive tracheal cultures in the 30 days following tracheostomy. Int J Pediatric Otorhinolaryngol. 2020;134:110028. https://doi.org/10.1016/j.ijporl.2020.110028.

58. Woods R, Geyer L, Mehanna R, Russell J. Pediatric tracheostomy first tube change: when is it safe? Int J Pediatric Otorhinolaryngol. 2019;120:78-81.

59. Kohn J, McKeon M, Munhall D, Blanchette S, Wells S, Watters K. Standardization of pediatric tracheostomy care with "Go-bags". Int J Pediatric Otorhinolaryngol. 2019;121:154-6. https://search. datacite.org/works/10.1016/j.ijporl.2019.03.022. https://doi.org/ 10.1016/j.ijporl.2019.03.022.

60. Cristea AI, Jalou HE, Givan DC, Davis SD, Slaven JE, Ackerman VL. Use of polysomnography to assess safe decannulation in children. Pediatric Pulmonol. 2016;51(8):796-802. https:// onlinelibrary.wiley.com/doi/abs/10.1002/ppul.23395. https://doi. org/10.1002/ppul.23395. This retrospective study's findings regarding success rate with a pediatric decannulation protocol are summarized in Table 2.

61. Bandyopadhyay A, Cristea AI, Davis SD, Ackerman VL, Slaven JE, Jalou HE, et al. Retrospective analysis of factors leading to pediatric tracheostomy decannulation failure. A single-institution experience. Ann Am Thoracic Soc. 2017;14(1):70-5. https:// www.ncbi.nlm.nih.gov/pubmed/27768853. https://doi.org/10. 1513/AnnalsATS.201607-553OC. This retrospective study's findings regarding success rate with a pediatric decannulation protocol are summarized in Table 2.
62. Wirtz N, Tibesar RJ, Lander T, Sidman J. A pediatric decannulation protocol. Otolaryngol-Head Neck Surg. 2016;154(4):731-4. https://journals.sagepub.com/doi/full/10.1177/ 0194599816628522. https://doi.org/10.1177/0194599816628522. This retrospective study's findings regarding success rate with a pediatric decannulation protocol are summarized in Table 2.

63. Maslan J, Feehs K, Kirse D. Considerations for the successful decannulation of the pediatric patient: a single surgeon's experience. Int J Pediatric Otorhinolaryngol. 2017;98:116-20. https:// www.clinicalkey.es/playcontent/1-s2.0-S0165587617301799. https://doi.org/10.1016/j.ijporl.2017.04.038. This retrospective study's findings regarding success rate with a pediatric decannulation protocol are summarized in Table 2.

64. Pozzi M, Galbiati S, Locatelli F, Clementi E, Strazzer S. Performance of a tracheostomy removal protocol for pediatric patients in rehabilitation after acquired brain injury: factors associated with timing and possibility of decannulation. Pediatric Pulmonol. 2017;52(11):1509-17. https://onlinelibrary.wiley.com/doi/abs/ 10.1002/ppul.23832. https://doi.org/10.1002/ppul.23832. This retrospective study's findings regarding success rate with a pediatric decannulation protocol are summarized in Table 2.

65. Seligman KL, Liming BJ, Smith RJH. Pediatric tracheostomy decannulation: 11-year experience. Otolaryngol-Head Neck Surg. 2019;161(3):499-506. https://journals.sagepub.com/doi/full/ 10.1177/0194599819842164. https://doi.org/10.1177/ 0194599819842164 . This retrospective study's findings regarding success rate with a pediatric decannulation protocol are summarized in Table 2.

66. Morrow AK, Tunkel DE, Collaco JM, McGrath-Morrow S, Lam JC, Accardo JA, et al. The role of polysomnography in decannulation of children with brain and spinal cord injuries. Pediatric Pulmonol. 2018;54(3):333-41. https:// search.datacite.org/works/10.1002/ppul.24208. https://doi.org/10. 1002/ppul.24208. This retrospective study's findings regarding success rate with a pediatric decannulation protocol are summarized in Table 2.

67. Beaton F, Baird T, Clement WA, Kubba H. Tracheostomy decannulation at the royal hospital for sick children in glasgow: predictors of success and failure. Int J Pediatric Otorhinolaryngol. 2016;90:204-9. https://www.clinicalkey.es/playcontent/1-s2.0 S0165587616302191. https://doi.org/10.1016/j.ijporl.2016.07. 013 . This retrospective study's findings regarding success rate with a pediatric decannulation protocol are summarized in Table 2.

68. Lee J, Soma MA, Teng AY, Thambipillay G, Waters KA, Cheng AT. The role of polysomnography in tracheostomy decannulation of the paediatric patient. Int J Pediatric Otorhinolaryngol. 2016;83: 132-6. https://www.clinicalkey.es/playcontent/1-s2.0S0165587616000537. https://doi.org/10.1016/j.ijporl.2016.01. 034. This retrospective study's findings regarding success rate with a pediatric decannulation protocol are summarized in Table 2 .

69. Schweiger C, Manica D, Lbianco Neto JF, et al. Determinants of successful tracheostomy decannulation in children: a multicentric cohort study. J Laryngol Otol. 2020;134:63-7. https://doi.org/10. 1017/S0022215119002573.

Publisher's Note Springer Nature remains neutral with regard to jurisdictional claims in published maps and institutional affiliations. 